\title{
DNA methylation as mechanism of apoptotic resistance development in endometrial cancer patients
}

\author{
Veronika Fialkova ${ }^{1}$, Eva Vidomanova ${ }^{2}$, Tomas Balharek ${ }^{3}$, Juraj Marcinek ${ }^{3}$, Erik Kudela ${ }^{4}$, \\ Sandra Hanysova ${ }^{1}$, Jozef Visnovsky ${ }^{4}$, Dusan Dobrota ${ }^{1}$ and Jozef Hatok ${ }^{1,2}$ \\ ${ }^{1}$ Department of Medical Biochemistry, Jessenius Faculty of Medicine in Martin, Comenius University in Bratislava, Martin, \\ Slovakia \\ ${ }^{2}$ Biomedical Center Martin, Jessenius Faculty of Medicine in Martin, Comenius University in Bratislava, Martin, \\ Slovakia \\ ${ }^{3}$ Department of Pathological Anatomy, Jessenius Faculty of Medicine in Martin, Comenius University in Bratislava, Martin, \\ Slovakia \\ ${ }^{4}$ Department of Gynecology and Obstetrics, Jessenius Faculty of Medicine in Martin, Comenius University in Bratislava, \\ Martin, Slovakia
}

\begin{abstract}
DNA methylation is a significant epigenetic modification which plays a key role in regulation of gene expression and influences functional changes in endometrial tissue. Aberrant DNA methylation changes result in deregulation of important apoptotic proteins during endometrial carcinogenesis and apoptosis resistance development. Evading apoptosis is still a major problem in the successful treatment of endometrial cancer patients. The aim of our study was to examine the promoter DNA methylation changes in 22 apoptosis-associated genes in endometrioid endometrial cancer patients, precancerous lesions and healthy tissue from various normal menstrual cycle phases using a unique pre-designed methylation platform. We observed as the first a significant difference in promoter DNA methylation status in genes: BCL2L11 $(p<0.001), C I D E B(p<0.03)$ and GADD45A $(p<0.05)$ during endometrial carcinogenesis and BIK gene $(p<0.03)$ in different phases of normal menstrual cycle. The results of our study indicate that deregulation of mitochondrial apoptotic pathway can considerably contributes to the apoptosis resistance development and may be helpful in identifying of new potent biomarkers in endometrial cancer.
\end{abstract}

Key words: DNA methylation — Apoptosis — Endometrial cancer — Menstrual cycle

\section{Introduction}

Identifying molecular changes that distinguish normal healthy tissue from precancerous and tumor tissue has become a topic area of intensive interest for many molecular oncologists. It has been proposed a new molecular mechanism of carcinogenesis in which DNA hypermethylation in many cancer-associated genes promoter regions leads to the gene inactivation (Esteller 2002). Study of epigenetic mechanisms (including DNA methylation, covalent histone

Correspondence to: Jozef Hatok, Department of Medical Biochemistry, Jessenius Faculty of Medicine in Martin, Comenius University in Bratislava, Mala Hora 11161/4D, SK-03601 Martin, Slovakia E-mail: hatok@jfmed.uniba.sk modifications, nucleosome positioning and noncoding RNA molecules) is a very popular and expending field in biomedical cancer research. Currently, many developing chemical compounds, which target specific enzymes of epigenetic machinery has become a promising anticancer strategy (Tao and Freudenheim 2010; Ma and Gao 2014).

DNA methylation is the most widely studied epigenetic mechanism which has a crucial role in the regulation of gene expression. This biochemical modification is catalyzed by DNA methyltransferases which transfer the methyl group from $\mathrm{S}$-adenosylmethionine to the cytosine residues to form 5-methylcytosine (Lim and Maher 2010). Recent studies showed that changes in DNA methylation pattern are related to changes in DNA methyltransferase expression levels which are under the control of ovarian steroid 
hormones and their nuclear receptors during the proliferative and secretory phases of menstrual cycle (Yamagata et al. 2009; Munro et al. 2010; Vincent et al. 2011). DNA methylation plays a key role in the regulation of genes involved in cell growth, proliferation and also apoptosis in endometrial tissue (Caplakova et al. 2016). Deregulation of DNA methylation pattern can thus disrupt cell homeostasis of the endometrium and results in endometrial cancer development (Ma and Gao 2014).

Endometrial cancer (EC) is now the most common malignant tumor of the female genital organs in developed countries including Slovakia with still increasing incidence (Krajcovicova et al. 2009; Ferlay et al. 2012). The majority of patients with sporadic endometrial cancers (approximately $80 \%$ ) comprise of type I or estrogen-dependent endometrioid endometrial adenocarcinomas (Llauradó et al. 2012). Prolonged exposure to estrogen promotes the development of endometrial hyperplasia, which may be without and with atypia. Atypical hyperplasia (AH), also called endometrioid intraepithelial neoplasia (EIN), shows $20-43 \%$ risk of progression to the type I of EC (Setiawan et al. 2013; Lai et al. 2014). The type II EC, which represents broadly $20 \%$ of endometrial carcinomas cases, usually have non-endometrioid histology and are poorly differentiated. Hysterectomy is the main treatment for patients with $\mathrm{AH}$ and for patients in early stages of EC. Whereas the standard care for patients with advanced and recurrent disease is still based on using combination of chemotherapy and radiotherapy. Response to therapy is an important factor, which favours the prognosis and overall survival of EC patients.

One of the major goals of cancer therapy is to trigger apoptosis, which is often disrupted in patients with advanced disease. Apoptosis is conserved program cell death which, in response to extrinsic and intrinsic death stimuli, leads to the activation of a family of cysteine proteases, caspases (Wong 2011). Apoptotic death is mediated through two pathways: the extrinsic (death receptor pathway) and intrinsic (mitochondrial) pathway, which is regulated by proteins of the B-cell lymphoma 2 (Bcl-2) family (Hatok and Racay 2016). Dysregulation in expression of $\mathrm{Bcl}$-2 family genes (pro-/antiapoptotic) in non-malignant cells may result in uncontrolled proliferation, the disorganized growth of tissue cells and tumor development (Blahovcova et al. 2015). Further, apoptosis is the crucial process maintaining cellular homeostasis during the menstrual cycle by elimination of senescent cells from the functional layer of the uterine endometrium during the late secretory and menstrual phases of the cycle (Zubor et al. 2009). There are various stress-inducing signals which disrupt the physiological functions of endometrial cells and ultimately may trigger tumorigenesis based on resistance to apoptosis. Aberrant DNA methylation pattern can be one of the major mechanisms which promote the ability of cancer cells to evade apoptosis and thus contribute to therapeutic resistance (Fulda 2009; Nachajova et al. 2015). Despite that there are only a few studies dealing with the aberrant DNA methylation status in apoptosis-associated genes in EC.

In our study we aimed to investigate the aberrant methylation of $\mathrm{CpG}$ islands within the promoter regions of selected apoptotic regulators in patients with endometrial cancer, precancerous lesion compared with healthy controls in order to define methylation changes during endometrial carcinogenesis and those that occur during normal menstrual cycle.

\section{Materials and Methods}

\section{Patients and clinical samples}

This study enrolled 51 subjects who were operated at Department of Gynecology and Obstetrics and examined at Department of Pathological Anatomy in collaboration with Department of Medical Biochemistry of Jessenius Faculty of Medicine in Martin, Comenius University in Bratislava. All patients were Caucasians, the residents of the geographic area of the Slovakia. They underwent surgery (hysteroscopy, uterine curettage or hysterectomy) during the study period. The obtained native tissue samples with size 3-5 $\mathrm{mm}^{3}$ (25-75 $\mathrm{mg}$ ) were placed into $1.5 \mathrm{ml}$ clear tubes containing stabilization reagent (RNAlater ${ }^{\oplus}$, Qiagen) and stored at $-80^{\circ} \mathrm{C}$ for later methylation analysis. The tissue samples were histologically examined by pathologist and divided into three groups: Normal endometrium $(n=22)$, Precancerous lesion $(n=7)$, and Endometrioid endometrial cancer $(n=22)$ (Tab. 1$)$.

Table 1. The characterization of examined groups of patients

\begin{tabular}{llcc}
\hline Examined groups & Histological features & $n$ & Age (years) \\
\hline \multirow{3}{*}{ Normal endometrium } & Proliferative endometrium (PE) & 7 & $44.6 \pm 5.8$ \\
& Secretory endometrium (SE) & 8 & $46.0 \pm 4.2$ \\
\multirow{2}{*}{ Precancerous lesion } & Atrophic endometrium (AE) & 7 & $53.9 \pm 3.2$ \\
\cline { 2 - 4 } Endometrial cancer & Atypical hyperplasia (HA) & 7 & $54.6 \pm 4.7$ \\
\cline { 2 - 4 } & Low grade EEC (EEC-L) & 14 & $63.1 \pm 9.6$ \\
& High grade EEC (EEC-H) & 8 & $66.8 \pm 9.3$ \\
\hline
\end{tabular}


The exclusion criteria were the history of previous gynecological malignancy or synchronous malignancy and cases with an endometrial malignancy other than endometrioid type of endometrial adenocarcinomas, including clear cell or serous histological type. Tumor typing was carried out according to the WHO Classifications of Tumours of Female Reproductive Organs (2014) (Kurman et al. 2014) and Tumor staging and grading was determined according to the TNM FIGO classification (2009) (Pecorelli 2009). Endometrioid endometrial cancer represent a range of neoplasms, from well to poorly differentiated tumours (low to high grade), where serous and clear-cell carcinomas are high grade by definition. Low grade EC (in our case $n=14$ ) are often seen in premenopausal women, are associated with indolent clinical behaviour. By contrast, serous carcinomas (high grade, $n=8$ ) frequently develop in postmenopausal women in association with atrophic endometrium, and generally show an aggressive clinical course (Murali et al. 2014; Kajo et al. 2015). The frozen tissue samples were processed for genomic DNA isolation. Only samples with successful DNA extraction and sufficient DNA quality were included in the methylation analysis.

\section{Ethics approval}

This study was approved by the Ethics Committee of the Jessenius Faculty of Medicine in Martin (registered under IRB00005636 at Office for Human Research Protection, U.S. Department of Health and Human Services) under the code FK 1255/2013. Informed consent was obtained from all subjects of this study.

\section{Genomic DNA isolation from endometrial tissue}

Genomic DNA stored at stabilization reagent (RNAlater ${ }^{\circ}$, Qiagen) from endometrial tissue was extracted using commercially available Wizard Genomic DNA Purification Kit (Promega) according to the manufacturer's instructions. The DNA purity and concentration of tissue samples was estimated by measuring the absorbance at $260 \mathrm{~nm}$ using a Nanophotometer (Implen).

\section{DNA methylation detection of human apoptosis genes}

To detect promoter methylation status of a panel of 22 apoptosis associated genes we used unique methylation platform, EpiTect Methyl II Signature PCR Array (22) Kit (Qiagen). The method is based on detection of remaining input DNA after cleavage with a methylation-sensitive and/ or a methylation-dependent restriction enzymes by using real-time PCR. We performed the restriction digestion using the EpiTect Methyl II DNA Restriction Kit (Qiagen) following the manufacturer's protocol. Briefly, $2 \mu \mathrm{g}$ purified genomic DNA was mixed with $100 \mu 15 \times$ Restriction Digestion Buffer and with additional volume of nuclease-free water in a final volume of $470 \mu \mathrm{l}$. The reaction mixture was thoroughly mixed and briefly centrifuged in a microcentrifuge. We prepared 4 digestion reactions (Mo, Ms, Md, Msd). Subsequently, $116 \mu \mathrm{l}$ reaction mixture was mixed with $2 \mu \mathrm{l}$ methylation-sensitive enzyme in Ms mixture, $2 \mu \mathrm{l}$ methylation-dependent enzyme in Md mixture and with $2 \mu \mathrm{l}$ of both enzymes in Msd mixture, whereas Mo mixture did not obtain these enzymes. The nuclease-free water was added to the final volume of $30 \mu \mathrm{l}$ and reaction mix was thoroughly spined. The reactions were incubated at $37^{\circ} \mathrm{C}$ overnight and enzymes were inactivated by heating at $65^{\circ} \mathrm{C}$ for $20 \mathrm{~min}$. Following digestion, the remaining DNA was quantified by real-time PCR using primers that flanked promoter regions of candidate genes. The PCR reaction containing $330 \mu \mathrm{RT}^{2} \mathrm{SYBR}^{\circ}$ Green ROX ${ }^{\mathrm{TM}}$ qPCR Mastermix (24) (Qiagen), $30 \mu$ ldigestion reaction mix separately and $300 \mu \mathrm{l}$ nuclease-free water was carried out in a total volume of $25 \mu \mathrm{l}$ per reaction in 96-well PCR Array plate containing pre-aliquoted primer mixes. The reactions were detected using a cycler ViiA7 Real-Time PCR System (Applied Biosystems) with the following thermal cycling program: initial denaturation at $95^{\circ} \mathrm{C}$ for $10 \mathrm{~min}$, followed by 3 cycles at $99^{\circ} \mathrm{C}$ for $30 \mathrm{~s}$ and at $72^{\circ} \mathrm{C} 1 \mathrm{~min}$ and 40 detecting cycles at $97^{\circ} \mathrm{C}$ for $15 \mathrm{~s}$ and at $72^{\circ} \mathrm{C}$ for $1 \mathrm{~min}$. The Mo reaction represents the total amount of input DNA for RT-PCR. The hypermethylated DNA was detected in Ms reaction, Md was represented by unmethylated DNA and Msd by background of input undigested DNA.

\section{Statistical analysis}

The methylation status of gene promoter regions (the relative amount of methylated an unmethylated DNA fractions) was calculated using analysis program provided by manufacturer EpiTect Methyl II PCR Array Microsoft Excel (Qiagen, Germany) using $\Delta$ Ct method. Comparison of DNA methylation levels between examined groups was performed using Student's t-test. The data in the columnar figures represent average values \pm SEM for examined samples.

\section{Results}

The study included 51 patients, who were hospitalized at Department of Gynecology and Obstetrics JFM CU and University Hospital in Martin, in the years 2013-2016, for surgical treatment and were selected for final analysis due to sufficient DNA extraction and quality. Patients on the basis of histopathological finding were divided into different groups: $\mathrm{PE}$, proliferative endometrium; SE, secretory endometrium; $\mathrm{AE}$, atrophic endometrium; HA, atypic hyperplasia; EEC-L, low grade endometrioid endometrial cancer; and EEC-H, high grade endometrioid endometrial cancer (Tab. 1). 
With the aim to investigate DNA methylation changes that occur during endometrial carcinogenesis from those in normal menstrual cycle and considering the different mean age between samples of normal endometrium, we selected $\mathrm{PE}$ and SE patients and investigated them independently from other groups (Tab. 1). Whereas atrophic endometrium samples were used as nonmalignant healthy controls to the endometrial cancer samples and precancerous lesions. Mean age of the HA patients was $54.6( \pm 4.7)$ years, the mean age of the ECC-L patients was $63.1( \pm 9.6)$ years and $66.8( \pm 9.3)$ years for the EEC-H patients.

We found a significantly higher age of EEC patients compared to the HA patients $(p<0.007)$, but there was no significant difference in age between HA and AE patients and also between patients with low and high grade of EEC. We also did not find a relevant difference in age between the groups of SE and PE patients.

Due to better interpretation of our results, we divided analysed apoptotic genes $(n=22)$ into two groups: genes involved in intrinsic apoptotic pathway and genes of TNF (Tumor Necrosis Factor) pathway or extrinsic apoptotic pathway (Tab. 2).
We found that the majority of all analysed genes in studied groups was characterized by increased fraction of unmethylated DNA (in \%), expect for TNFRSF25 gene which was hypermethylated in promoter region but with no significant relevance between all groups (Fig. 1). According to the results of methylated DNA fractions we were interested in genes with methylated DNA threshold $>25 \%$. There were included genes: BCL2L11, BIK, CIDEB, GADD45A, HRK and TNFRSF25. Majority of them was genes regulated intrinsic apoptotic pathway (Fig. 1), except for TNFRSF25 included in TNF apoptotic pathway (Fulda 2009).

When we focused on DNA methylation changes in investigated groups during normal menstrual cycle, we detected only change of the BIK promoter methylation status. The gene methylation level was higher in proliferative endometrium compared to the secretory endometrium $(p=0.03)$ (Fig. 2A).

A significant difference of the promoter $\mathrm{CpG}$ methylation status was detected in BCL2L11, BIK, CIDEB and GADD45A between the studied groups. The DNA methylation level of BCL2L11 promoter region increased progressively with enhancing endometrial cancer grade $(p=0.0018$ were

Table 2. Gene specific DNA methylation targets included in PCR array

\begin{tabular}{lll}
\hline Gene ID & Symbol & Description \\
\hline \multicolumn{2}{c}{ Intrinsic apoptotic pathway } & \\
\hline 317 & APAF1 & Apoptotic peptidase activating factor 1 \\
581 & BAD & BCL2-associated agonist of cell death \\
10018 & BAX & BCL2-associated X protein \\
9774 & BCL2L11 & BCL2-like 11 \\
637 & BCLAF1 & BCL2-associated transcription factor \\
638 & BID & BH3 interacting domain death agonist \\
329 & BIK & BCL2-interacting killer \\
665 & BIRC2 & Baculoviral IAP repeat containig 2 \\
836 & BNIP3L & BCL2/adenovirus E1B 19 kDa interacting protein 3-like \\
842 & CASP3 & Caspase3, apoptosis-related cysteine peptidase \\
27141 & CASP9 & Caspase 9, apoptosis-related cysteine peptidase \\
1676 & CIDEB & Cell death-inducing DFFA-like effector b \\
1647 & DFFA & DNA fragmentation factor, 45 kDa, alpha polypeptide \\
8739 & GADD45A & Growth arrest and DNA damage-inducible, alpha factor \\
7157 & HRK & Harakiri, BCL2 interacting protein \\
\hline & TP53 & Tumor protein p53 \\
\hline 8738 & Extrinsic apoptotic pathway & \\
1612 & CRADD & CASP2 and RIPK1 domain contaning adaptor with death domain \\
8772 & DAPK1 & Death-associated protein kinase 1 \\
4055 & FADD & Fas(TNFRSF6)-associated via death domain \\
27242 & LTBR & Lymphotoxin beta receptor (TNFR superfamily, member 3) \\
8718 & TNFRSF21 & Tumor necrosis factor receptor superfamily, member 21 \\
\hline & TNFRSF25 & Tumor necrosis factor receptor superfamily, member 25 \\
\hline
\end{tabular}




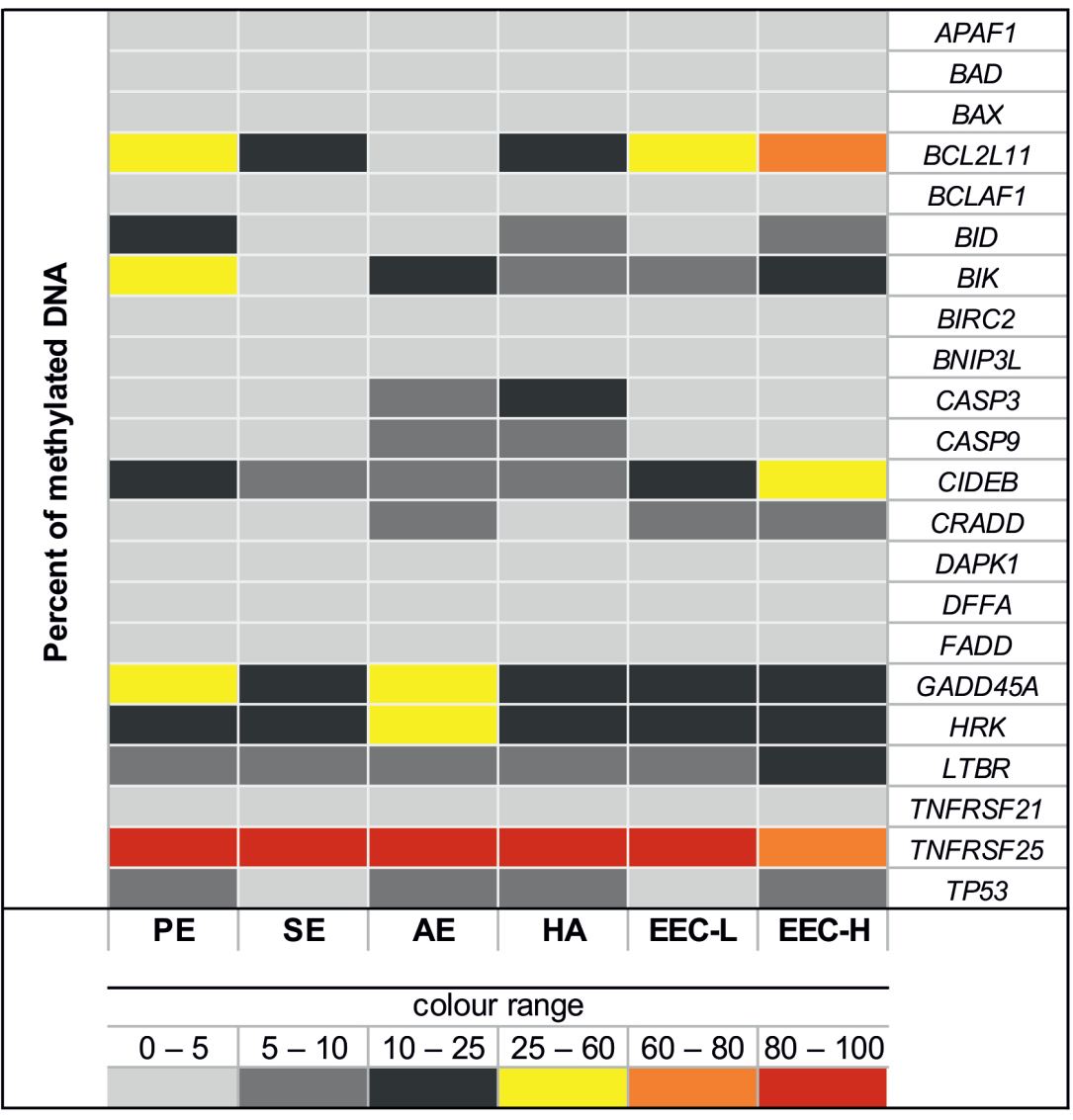

Figure 1. DNA methylation level in apoptosis-asocciated genes in studied groups: PE, proliferative endometrium; SE, secretory endometrium; $\mathrm{AE}$, atrophic endometrium; HA, hyperplasia with atypia; EEC-L, low grade endometrioid endometrial cancer; EEC-H, high grade endometrioid endometrial cancer. detected between patients with HA and EEC-L, $p=0.0009$ between HA and EEC-H, $p=0.0003$ between AE and EEC$\mathrm{L} / \mathrm{EEC}-\mathrm{H}$, whereas we did not observe a significant difference in methylation level between HA and AE groups) (Fig. $2 \mathrm{~B})$. The methylation status was significantly increased in group of EEC-H patients compared to the healthy controls of the CIDEB gene $(p=0.03)$, whereas in the case of the $G A D D 45 A$ gene there was observed significantly enhanced DNA methylation status between these groups $(p=0.046)$ (Fig. 2C and 2D).

\section{Discussion}

Resistance of cells to apoptosis is the major problem in successful treatment of endometrial carcinomas, the most common gynaecological malignancy in developed countries (Ferlay et al. 2012). Abnormalities in DNA methylation levels accompany early stages of endometrial carcinogenesis and may influence gene expression levels resulted in deregulation of apoptosis-associated genes (Tao and Freudenheim 2010; $\mathrm{Ma}$ and Gao 2014). Nowadays there are only a few scientific publications which have demonstrated DNA methylation status in apoptotic regulators during endometrial carcino- genesis and also during normal menstrual cycle (Zysman et al. 2002; Salvesen et al. 2004; Arafa et al. 2008; Liao et al. 2008; Pallares et al. 2008; Fiolka et al. 2013). In our study we investigated DNA methylation status of 22 apoptosisassociated genes in endometrial cancer tissue and healthy tissue using a commercially available methylation platform, EpiTect Methyl II Signature PCR Array (22) Kit (Qiagen). We detected the promoter DNA methylation changes with significant relevance of endometrial cancers compared to the controls (atrophic endometrium) in three genes: BCL2L11, $C I D E B$ and GADD45A. They are engaged in regulating of intrinsic apoptotic pathways. Previous studies on different human cancers have analysed and confirmed the DNA methylation changes in these genes, but none of them were demonstrated these changes in EC (Wang et al. 2005; San Jose-Eneriz et al. 2009; Perugini et al. 2013; Cho et al. 2014; Kucuk et al. 2015; Reis et al. 2015).

The most significant DNA methylation change was found in BCL2L11 gene, in which DNA methylation status was markedly increasing with a malignant phenotype of endometrial tissue. The biggest difference in DNA methylation was detected between atrophic endometrium $(<5 \%$ methylated DNA) and high-grade endometrioid endometrial cancer (> 60\% methylated DNA). Gene BCL2L11, at 2q.13 posi- 
A

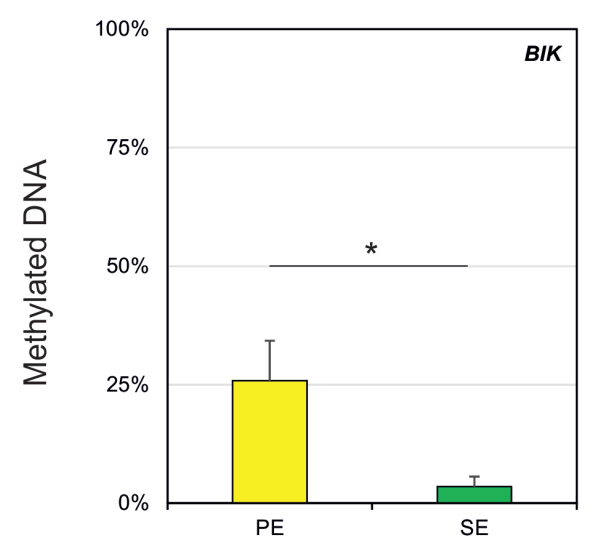

B

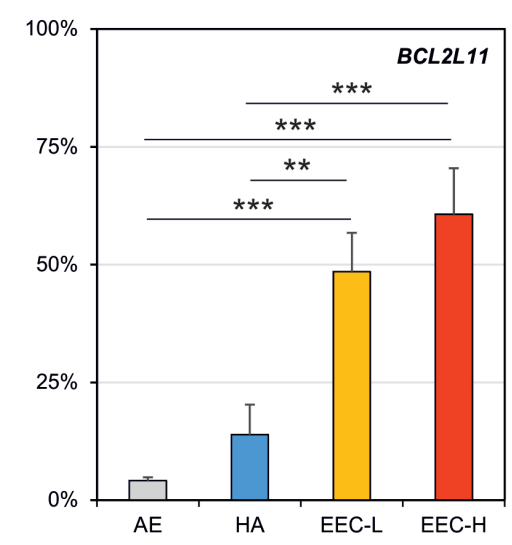

C

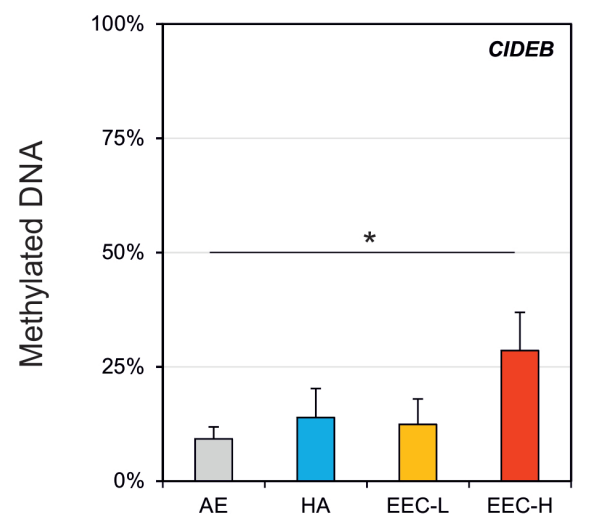

D

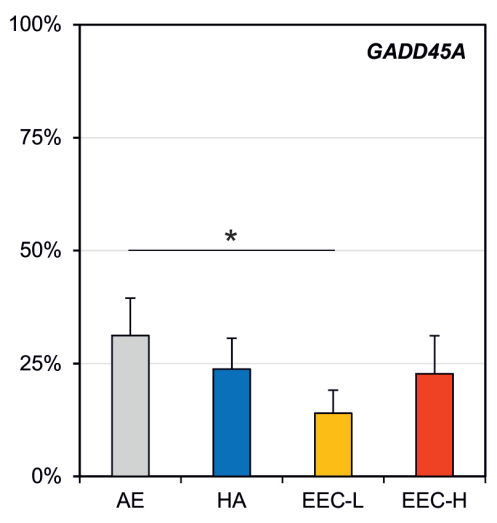

Figure 2. DNA methylation level in promoter regions of significantly changed apoptotic genes in studied groups. A. BIK promoter methylation level; B. BCL2L11 promoter methylation level; C. CIDEB promoter methylation level; D. GADD45A promoter methylation level. $\mathrm{PE}$, proliferative endometrium; SE, secretory endometrium; AE, atrophic endometrium; HA, hyperplasia with atypia; EEC-L, low grade endometrioid endometrial cancer; EEC-H, high grade endometrioid endometrial cancer. ${ }^{\star} p<0.05$; $^{* *} p<0.01$ and ${ }^{* * *} p<0.001$. tion, codes for pro-apoptotic BH3-only protein BIM which is a major inhibitor and agonist of Bcl-2 family proteins and results in activation of the pro-apoptotic proteins BAX and BAK (Fletcher and Huang 2008). Many previous studies confirmed epigenetic inactivation of BIM due to promoter hypermethylation in specific cancer types including leukemias, lymphomas and solid tumors which occurs through recruitment of the SIN3a/HDAC1/2 corepressor complex into its regulatory region (Mestre-Escorihuela et al. 2007; Zantl et al. 2007; San Jose-Eneriz et al. 2009; Kucuk et al. 2015). They also showed that down-regulation of BIM is associated with poor prognosis of cancer patients and can be restored using by epigenetic modulators (San Jose-Eneriz et al. 2009; Piazza et al. 2013). Our results suggested that BCL2L11 methylation can be used as biomarker for detection of early stages of EC and distinction of high-grade endometrioid carcinomas.

We observed the significantly increased DNA methylation level in patiens with EEC-H compared to healthy controls in $C I D E B$ gene. The protein encoded by the gene $C I D E B$, located on chromosome 14q.12, is a member of CIDE (cell death-inducing DFF45-like effector) protein family. Protein CIDEB is endoplasmatic reticulum- and lipid droplet membrane-associated protein, which plays an important role in very-low-density lipoprotein maturation and it is associated with development of obesity which constitutes a risk factor of EC development (Ye et al. 2009). In cancer cells expression of CIDEB is controlled by methylation of CpG islads. Recent studies demonstrated its hypermethylation status in lung, colon, renal and breast cancer where it is correlated with expression levels, poor clinical outcome and progression of cancer (Kamalakaran et al. 2011; Yu et al. 2013; Cho et al. 2014). Yu et al. suggested that CIDEB may be used as a novel prognostic marker in renal cell carcinoma (Yu et al. 2013). We were the first who demonstrated CIDEB methylation change in EC. It seems that $C I D E B$ methylation can markedly contribute to the apoptosis resistance development and also therapeutic resistance, but its precise role in apoptosis development must be elucidated by other studies.

In contrast to the methylation levels of BCL2L11 and $C I D E B$ genes our results showed significantly higher methylation level in AE compared to the EEC-L in GADD45A 
gene. The "Growth Arrest and DNA Damage-inducible 45" gene is located on chromosome $1 \mathrm{p} 31.3$ and codes for small protein belonging to the evolutionarily conserved GADD45 protein family which is induced by many environmental stress agents and DNA damage (Hollander et al. 1993; Cretu et al. 2009). Recently it was showed its function in DNA demethylation process and gene activation (Li et al. 2015). This protein also plays an important role in inducing of apoptotic cell death. Overexpression of GADD45A causes dissociation of BIM from the microtubule-associated components and translocation to mitochondria (Tong et al. 2005). So far increased DNA methylation level in promoter region of $G A D D 45 A$ gene was observed in breast, prostate cancer and acute myeloid leukemia where it is associated with decreased expression level, poor prognosis a might be useful as marker to distinguish benign $v s$. malignant solid tumors (Perugini et al. 2013; Reis et al. 2015). These result are inconsistent with ours, thus we can only suggest that methylation of GADD $45 A$ gene can be included in EEC-L development.

Cell proliferation, differentiation, regression and programmed cell death in different physiological phases during normal menstrual cycle is regulated by ovarian steroid hormones. They can interact with components of DNA methylation machinery to induce many target genes included in intracellular signalling cascade, cell proliferation and also apoptosis (Zelenko et al. 2012). In our work we noticed only significantly higher $B I K$ promoter methylation status in proliferative endometrium compared to the secretory endometrium. Protein BIK encoded by the gene BIK, at 22q13.2 position, is a pro-apoptotic $\mathrm{BH} 3$ protein that binds to the BAX and BAK proteins and activates them (Chinnadurai et al. 2008). Higher methylation level of BIK gene can correlate with increased expression level of DNA methyltransferases and estrogen level in proliferative menstrual phase, but its precise role in this tissue have not been studied yet (Yamagata et al. 2009; Vincent et al. 2011).

In present study we observed for the first time DNA methylation changes in apoptosis-associated genes including BCL2L11, CIDEB and GADD45A during endometrial carcinogenesis. Defects that occur in these genes may influence mitochondrial apoptotic pathway leading to acquired resistance to apoptosis and thus therapeutic resistance. We also demonstrated change of BIK methylation in various biological phases during normal menstrual cycle. It seems that genes regulating intrinsic apoptotic pathway play a key role in maintaining of endometrial cellular homeostasis. Knowledge of disrupted gene regulation in DNA methylation level during normal menstrual cycle and endometrial carcinogenesis can be helpful to distinguish healthy and cancer tissue and may improve the developing of new anticancer epigenetic strategies in EC patients.
Acknowledgements. This work was supported by the Slovak research and Development Agency under the Contract No. APVV0224-12, by the Grant of Comenius University No. UK/38/2016 and is the result of the project implementation: "CREATING A NEW DIAGNOSTIC ALGORITHM FOR SELECTED CANCER DISEASES", ITMS code 26220220022 supported by the Operational Programme Research and Innovation funded by the ERDF.

Conflict of interest. Authors declare no conflict of interest.

\section{References}

Arafa M., Kridelka F., Mathias V., Vanbellinghem J. F., Renard I., Foidart J. M., Boniver J., Delvenne P. (2008): High frequency of RASSF1 and RARb2 gene promoter methylation in morphologically normal endometrium adjacent to endometrioid adenocarcinoma. Histopathology 53, 525-532

Blahovcova E., Richterova R., Kolarovszki B., Dobrota D., Racay P., Hatok J. (2015): Apoptosis-related gene expression in tumor tissue samples obtained from patients diagnosed with glioblastoma multiforme. Int. J. Mol. Med. 36, 1677-1684 https://doi.org/10.3892/ijmm.2015.2369

Caplakova V., Babusikova E., Blahovcova E., Balharek T., Zelieskova M., Hatok J. (2016): DNA Methylation Machinery in the Endometrium and Endometrial Cancer. Anticancer Res. 36, $4407-4420$

https://doi.org/10.21873/anticanres.10984

Cho Y., Turner N. D., Davidson L. A., Chapkin R. S., Carroll R. J., Lupton J. R. (2014): Colon cancer cell apoptosis is induced by combined exposure to the m-3 fatty acid docosahexaenic acid and butyrate through promoter methylation. Exp. Biol. Med. 239, 302-310

https://doi.org/10.1177/1535370213514927

Chinnadurai G., Vijayalingam S., Rashmi R. (2008): BIK, The founding member of the $\mathrm{BH} 3$-only family proteins: mechanisms of the cell death and role in cancer and pathogenesis. Oncogene 1, S20-29 https://doi.org/10.1038/onc.2009.40

Cretu A., Sha X., Tront J., Hoffman B., Lieberman D. A. (2009): Stress sensor Gadd45 genes as therapeutic targets in cancer. Cancer Ther. 7, 268-276

Esteller M. (2002): CpG island hypermethylation and tumor suppressor genes: a booming present, a brighter future. Oncogene 21, 5427-5440 https://doi.org/10.1038/sj.onc. 1205600

Ferlay J., Soerejomataram I., Dikshit R., Eser S., Mather C., Rebelo M., Parkin D. M., Forman D., Bray F. (2012): Cancer incidence and mortality worldwide: Sources, methods and major patterns in GLOBOCAN. Int. J. Cancer 136, E359-386 https://doi.org/10.1002/ijc.29210

Fiolka R., Zubor P., Janusicova V., Visnovsky J., Mendelova A., Kajo K., Lasabova Z., Plank L., Danko J. (2013): Promoter hypermethylation of the tumor-suppressor genes RASSF1A, GSTP1 and CDH1 in endometrial cancer. Oncol Rep. 30, 2878-2886 https://doi.org/10.3892/or.2013.2752 
Fletcher J. I., Huang D. C. (2008): Controlling the cell death mediators Bax and Bak: puzzles and conundrums. Cell Cycle 7, 39-44 https://doi.org/10.4161/cc.7.1.5178

Fulda S. (2009): Tumor resistance to apoptosis. Int. J. Cancer 124, 511-515 https://doi.org/10.1002/ijc.24064

Hatok J., Racay P. (2016): Bcl-2 family proteins: master regulators of cell survival. Biomol. Concepts 7, 259-270 https://doi.org/10.1515/bmc-2016-0015

Hollander M. C., Alamo I., Jackman J., Wang M. G., McBride O. W., Fornace A. J. Jr. (1993): Analysis of the mammalian gadd45 gene and its response to DNA damage. J. Biol. Chem. 268, 24385-24393

Kajo K., Vallová M., Biró C., Bognár G., Macháleková K., Závodná K., Galbavý Š., Žúbor P. (2015): Molecular pathology of endometrial carcinoma - a review. Cesk. Patol. 2, 65-73

Kamalakaran S., Varada V., Giercksky Russnes H. E., Levy D., Kendall J., Janevski A., Riggs M., Banerjee N., Synnestvedt M., Schlichting E., et al. (2011): DNA methylation pattrens in luminal breast cancers differ from non-luminal subtypes and can identify relapse risk independent of other clinival variables. Mol. Oncol. 5, 77-92 https://doi.org/10.1016/j.molonc.2010.11.002

Krajcovicova I., Safei Diba Ch., Sieberova G., Davidova A., Jakubcova E., Kajabova M., Kosecova M., Malinovska E., Naništova H. (2009): Cancer incidence in the Slovak Republic 2009. Publisher NHIC, Bratislava

Kücük C., Hu X., Jiang B., Klinkebiel D., Geng H., Gong Q., Bouska A., Igbal J., Gaulard P., McKeithan T. W., Chan W. C. (2015): Global promoter methylation analysis reveals novel candidate supressor genes in natural killer cell lymphoma. Clin. Cancer Res. 21, 1699-1711 https://doi.org/10.1158/1078-0432.CCR-14-1216

Kurman, R. J., Carcangiu M. L., Herrington, C. S., Young, R. H. (2014): WHO Classification of Tumours of Female Reproductive Organs. WHO Press, London

Li Z., Gu T. P., Weber A. R., Shen J. Z., Li B. Z., Xie Z. G., Yin R., Guo F., Liu X., Tang F., Wang H., Schar P., Xu G. L. (2015): Gadd45a promotes DNA demethylation through TDG. Nucleic Acids Res. 43, 3986-3997 https://doi.org/10.1093/nar/gkv283

Liao X., Siu M. K., Chan K. Y., Wong E. S., Ngan H. Y., Chan Q. K., Li A. S., Khoo U. S., Cheung A. N. (2008): Hypermethylation of RAS effector related genes and DNA methyltransferase 1 expression in endometrial carcinogenesis. Int. J. Cancer 123, 296-302 https://doi.org/10.1002/ijc.23494

Llauradó M., Ruiz A., Majem B., Ertekin T., Colás E., Pedrola N., Devis L., Rigau M., Sequeiros T., Montes M., et al. (2012): Molecular bases of endometrial cancer: new roles for new actors in the diagnosis and the therapy of the disease. Mol. Cell Endocrinol. 358, 244-255 https://doi.org/10.1016/j.mce.2011.10.003

Lai H. C., Wang Y. C., Yu M. H., Huang C. C., Yuan C. C., Chen K. J., Wu C. C., Chiang K. J., Chao T. K. (2014): DNA methylation as a biomarker for the detection of hidden carcinoma in endometrial atypical hyperplasia. Gynecol. Oncol. 135, 552-559 https://doi.org/10.1016/j.ygyno.2014.10.018
Lim D. H. K., Maher E. R. (2010): DNA methylation: a form of epigenetic control of gene expression. Obstetrician \& Gynaecologist 12, 37-42

https://doi.org/10.1576/toag.12.1.037.27556

Ma X., Gao X. (2014): Epigenetic modifications and carcinogenesis of human endometrial cancer. Austin J. Clin. Pathol. 1,1014

Mestre-Escorihuela C., Rubio-Moscardo F., Richter J. A., Siebert R., Climent J., Fresquet V., Beltran E., Marugan I., Marín M., Rosenwald A., et al. (2007): Homozygous deletions localize novel tumor supressor genes in B-cell lymphomas. Blood 109, $271-180$ https://doi.org/10.1182/blood-2006-06-026500

Munro S. K., Farguar C. M., Mitchell M. D., Ponnampalam A. P. (2010): Epigenetic regulation of endometrium during the menstrual cycle. Mol. Hum. Reprod. 16, 297-310 https://doi.org/10.1093/molehr/gaq010

Murali R., Soslow R. A., Weigelt B. (2014): Classification of endometrial carcinoma: more than two types. Lancet Oncol. 7, 268-278 https://doi.org/10.1016/S1470-2045(13)70591-6

Nachajova M., Mersakova S., Sivakova J., Krivus S., Szepe P., Hatok J., Adamkov M. (2015): New molecular aspects of endometrial carcinoma. Neuro. Endocrinol. Lett. 7, 638-643

Pallarés J., Velasco A., Eritja N., Santacano M., Dolcet X., Cuatrecasas M., Palomar-Asenjo V., Catasús L., Prat J., Matias-Guiu X. (2008): Promoter hypermethylation and reduced expression of RASSF 1 are frequent molecular alterations of endometrial carcinoma. Mod. Pathol. 21, 691-699

https://doi.org/10.1038/modpathol.2008.38

Pecorelli S. (2009): Revised FIGO staging for carcinoma of the vulva, cervix, and endomertium. Int. J. Gynaecol. Obstet. 105, 103-104 https://doi.org/10.1016/j.ijgo.2009.02.012

Piazza R., Magistroni V., Mogavero A., Andreoni F., Ambrogio C., Chiarle R., Mologni L., Bachmann P. S., Lock R. B., Collini P., Pelosi G., Gambacorti-Passerini C. (2013): Epigenetic silencing of the proapoptotic gene BIM in anaplastic large cell lymphoma through an MeCP2/SIN3a deacetylating complex. Neoplasia 15, 511-522 https://doi.org/10.1593/neo.121784

Perugini M., Larosii D. G., Kok Ch., Cimmings N., Diakiw S. M., Brown A. L., Danner S., Bardy P., Bik To L., Wei A. H., Lewis I. D., D'Andrea R. J. (2013). Gadd45A metyhlation predicts poor overal survival in acute myeloid leukemia and is associated with IDH1/2 and DNMT3A mutations. Leukemia 27, 1588-1592 https://doi.org/10.1038/leu.2012.346

Reis I. M., Ramachandran K., Speer C., Gordian E., Signal R. (2015): Serum GADD45a methylation is a useful biomarker to disdinguish benign vs malignant prostate disease. Br. J. Cancer 113, 460-468 https://doi.org/10.1038/bjc.2015.240

Salvesen H. B, Stefansson I., Kretzschmar E. I., Gruber P., MacDonald N. D., Ryan A., Jacobs I. J., Akslen L. A., Das S. (2004): Significance of PTEN alterations in endometrial carcinoma: a population-based study of mutations, promoter methylation and PTEN protein expression. Int. J. Oncol. 25, 1615-1623 https://doi.org/10.3892/ijo.25.6.1615

San José-Eneriz E., Aqirre X., Jiménez-Velasco A., Cordeu L., Martín V., Arqueros V., Gárate L., Fresquet V., Cervantes F., 
Martínez-Climent J. A. et al. (2009): Epigenetic down-regulation of BIM expression is associated with reduced optimal responses to imatinib treatment in chronic myeloid leukaemia. Eur. J. Cancer 45, 1877-1889 https://doi.org/10.1016/j.ejca.2009.04.005

Setiawan V. W., Yang H. P., Pike M. C., McCann S. E., Yu H., Xiang Y. B., Wolk A., Wentzensen N., Weiss N. S., Webb P. M., et al. (2013): Type I and II endometrial cancers: have they different risk factors? J. Clin. Oncol. 31, 2607-2618 https://doi.org/10.1200/JCO.2012.48.2596

Tao M. H., Freudenheim J. L. (2010): DNA methylation in endometrial cancer. Epigenetics 5, 491-498 https://doi.org/10.4161/epi.5.6.12431

Tong T., Li J., Jin S., Li X., Fan W., Song Y., Wang M., Liu Z., Wu M., Zhan Q. (2005): Gadd45a expression induces Bim dissociation from the cytoskeleton and translocation to mitochondria. Mol. Cell. Biol. 25, 4488-4450 https://doi.org/10.1128/MCB.25.11.4488-4500.2005

Vincent Z. L., Farguar C. M., Mitchell M. D., Ponnampalam A. P. (2011): Expression and regulation of DNA methyltransferases in human endometrium. Fertil. Steril. 95, 1522-1525 https://doi.org/10.1016/j.fertnstert.2010.09.030

Wong R. S. (2011): Apoptosis in cancer: from pathogenesis to treatment. J. Exp. Clin. Cancer Res. 30, 87 https://doi.org/10.1186/1756-9966-30-87

Wang W., Huper G., Guo Y., Murphy S. K., Olson J. A. Jr., Marks J. R. (2005): Analysis of methylation-sensitive transcriptome identifies GADD45a as a frequently methylated gene in breast cancer. Oncogene 24, 2705-2714 https://doi.org/10.1038/sj.onc.1208464

Yamagata Y., Asada H., Tamura I., Lee L., Maekawa R., Taniguchi K., Taketani T., Matsuoka A., Tamura H., Sugino N. (2009): DNA methyltransferase expression in the human endometrium: down-regulation by progesterone and estrogen. Hum. Reprod. 24, 1126-1132 https://doi.org/10.1093/humrep/dep015
Ye J., Li J. Z., Liu Y., Li X., Yang T, Ma X., Li Q., Yao Z., Li P. (2009): Cideb, an ER- and lipid droplet-associated protein, mediates VLDL lipidation and maturation by interacting with apolipoprotein B. Cell Metab. 9, 177-190 https://doi.org/10.1016/j.cmet.2008.12.013

Yu M., Wang H., Zhao J., Yuan Y., Wang C., Li J., Zhang L., Li Q., Ye J. (2013): Expression of CIDE proteins in clear cell renal cell carcinoma and their prognostic significance. Mol. Cell. Biochem. 378, 145-151 https://doi.org/10.1007/s11010-013-1605-y

Zantl N., Weirich G., Zall H., Seiffert B. M., Fisher S. F., Kirscher S. F., Hartmann C., Fritsch R. M., Gillissen B., Daniel P. T., Häcker G. (2007): Frequent loss of expression of the pro-apoptotic portein Bim in renal cell carcinoma: evidence for contribution to apoptosis resistance. Oncogene 26, 7038-7048 https://doi.org/10.1038/sj.onc.1210510

Zelenko Z., Aghajanova L., Irwin J. C., Giudice L. C. (2012): Nuclear receptors, coregulator signaling, and chromatin remodeling pathways suggest involvement of the epigenome in the steroid hormone response of endometrium and abnormalities in endometriosis. Reprod. Sci. 19, 152-162 https://doi.org/10.1177/1933719111415546

Zubor P., Hatok J., Galo S., Dokus K., Klobusiakova D., Danko J., Racay P. (2009): Anti-apoptotic and pro-apoptotic gene expression evaluated from eutopic endometrium in the proliferative phase of the menstrual cycle among women with endometriosis and healthy controls. Eur. J. Obstet. Gynecol. Reprod. Biol. 145, 172-176 https://doi.org/10.1016/j.ejogrb.2009.04.024

Zysman M., Saka A., Millar A., Knight J., Chapman W., Bapat B. (2002): Methylation of adenomatous polyposis coli in endometrial cancer occurs more frequently in tumors with microsatellite instability phenotype. Cancer Res. 62, 3663-3666

Received: April 3, 2017

Final version accepted: July 21, 2017 